\title{
Nursing in search of quality and resolution of Primary Care Health
}

\author{
Rosa Maria Godoy Serpa da Fonseca', Vânia Paula Stolte Rodrigues" \\ ' University of São Paulo, Nursing School. São Paulo-SP, Brazil. Scientific Department \\ of Primary Health Care, Brazilian Nursing Association. Brasilia-DF \\ "Faculty UNIGRAN Capital, Undergraduate Nursing Course. Campo Grande-MS. \\ President of ABEn Mato Grosso do Sul Section. Campo Grande-MS.
}

It was close from 13 pm on April 30, 2014 when sensations and feelings of relief, satisfaction, joy and especially of accomplishment crowned the words of the President of the Brazilian Association of Nursing by declaring the 4th National Seminar on Guidelines for Nursing Primary Health Care, 4th SENABS . As if by magic, such feelings faded hassles, difficulties, sadness, worry, anger, stress, crying, trembling and fear we have experienced in last months in the planning. Has not lacked pray and amulets, live and in color, the Internet, in thought ... All fine mixed to provide to participants and guests a Seminar of quality compatible with ours ( and theirs ) expectations and waits .

On the agenda, the discussion of nursing in the context of Primary Health Care, and in it, the Family Health Strategy and the many others themes that makes up much of the practice of public health nursing and community health. What has been our role in this scenario? Is it being too tight and the disjointed health practices and will be seeking to integrate? What are the big questions that permeate the work of nursing? Our practices are resolving or just reiterate the many inequities that are exposed to our people, our clients? We'll have answers or at least what to say in front of so many questions?

Questions like these (and many other) directed the syllabus (content and form) that guided us from 27 to 30 April 2014, under the bright sun and warm from Campo Grande, Mato Grosso do Sul. And this was not an event like so many others who have organized the Brazilian Nursing Association. It was the first of a management... This fact alone was already a cause for concern even more. Much work to brighten once more the collective construction of nursing knowledge of the Brazilian Nursing Association, this gentle lady who welcomes us, nurses, for over eight decades. Octogenarian respectable, but still very young in relation to place side by side with other areas of knowledge in terms of scientific output, each day has shown more willingness to defend and protect the interests of our profession and its workers in care to the population. In the context of primary care, almost half of them congregate.

To assist us to reflect, we picked a team of prominent not only in nursing but in many other areas. There were two conferences, four round tables, four thematic panels, various meetings and gatherings, led by experts who provided exposing your ideas, experiences, reflections and doubts that, like ours, I assure them that took many sleepless nights. That's why we had so much to say and is so even if we wanted to both listen to them and talk to them and they.

Like all other scientific events, the agenda reflected his time and our time is questionings, uncertainties and own insecurities of becoming a society in constant transformation and poignant, for good and for evil, in a time of effervescence in virtually all spheres of society and our daily lives. These concerns were embodied in the theme " Nursing Care in the resolution and quality of primary health care and its three main themes: 1 . Resolubility Nursing Care within the Primary Health Care; 2. Quality of Primary Health Care and Nursing Care; 3. Social visibility Nursing in Primary Care in Health.

The number of participants was considered small for the expected. We had about 450 people hanging out by the University Unigran Capital spaces, including regular subscribers, guests, visitors and other schools. Despite this, the same cannot be said for the quality. The interest of the participants can be found in rooms full all the time, with people remaining from beginning to end of the sessions, listening to the speakers and exhibitors coordinate communications, making inquiries, exchanging knowledge and experiences. The exhibition of electronic 
posters was considered another high point, both for the organization as for the participants.

One of the strategies used to enable and expand the discussions was not overlapping presentations of work with the conferences, roundtables and panels.

On the last day, given the context of the problems experienced in our country by nursing organizations, it has opened a space to discuss the specific issue of elections to the composition of COREn , including the Mato Grosso do Sul. As always, ABEn recognizes and reaffirms the strategic importance in acts of our organizations for the defense of the interests of our professional categories.

Like other ABEn events, the 4th SENABS enabled the alignment of the students. In addition to presenting papers, they could participate in the process of organizing the event and follow the discussions of the different thematic proposals. This kind of participation deserves by allowing the expansion of knowledge of Brazilian nursing, and fosters the development of critical thinking of future professionals entering them early in the real political landscape of the profession.

And so, once again, worthily fulfill our social role not only collectively build knowledge but also take the political nature of our work on the quality of life and health of our population and workers in nursing. Participants and members of the Organizing Committee, in marriage, joining forces and having as the dialectic (possible) utopia to build a beautiful and successful event, I believe we can make it honorable history of Brazilian nursing.

We thank the people who worked and participated, and especially to the deities who protected us and blessed during this journey! 